\title{
Application of Methods of Optimal Planning in the Meat and Dairy Subsector of the Agribusiness
}

\author{
Rasheed Kazbekovich Tuguz ${ }^{1}$, Georgy Valeryevich Tsalov ${ }^{1} \&$ Emma Aslanovna Hachemizova $^{2}$ \\ ${ }^{1}$ Adygei research Institute of Agriculture, Russian Federation \\ ${ }^{2}$ Maikop State Technological University, Maikop, Republic of Adygea \\ Correspondence: Rasheed Kazbekovich Tuguz, Lenin St., 48, item. Piedmont, Maikop, 385000, Republic of \\ Adygea.
}

\author{
Received: November 6, 2014 Accepted: December 6, 2014 Online Published: March 23, 2015 \\ doi:10.5539/ass.v11n8p277 URL: http://dx.doi.org/10.5539/ass.v11n8p277
}

\begin{abstract}
This article focuses on the problem of optimization of the current planning in the local meat and dairy agribusiness, determination of the optimal annual plan of production for all agricultural enterprises, meat and dairy plants, and refrigeration services providers using a system of models. The models that allow reproducing the behavior of economic systems in a very wide range of changing conditions, including those, which are difficult to observe in reality, or which are associated with a large region and significant costs.
\end{abstract}

Keywords: planning, meat and dairy subsector, agribusiness, production efficiency, optimal plans

\section{Introduction}

The most important object of production planning in a food production or processing enterprise is the output of products. Production planning is based on the distribution of the output between individual enterprises and production units. In the practice of planning the production of food manufacturers, the output distribution is a mechanical distribution of a program among enterprises and production units. At that, the volume of production is planned, based mainly on the projected capacity of enterprises. However, planning of the production program, which is satisfactory from the organizational and technical point, is not always satisfactory in economic terms without the use of modern tools.

\section{Methodology}

Formation of an economic-mathematical model assumes building a special table, in which all the economic, technological, and other conditions are formed in the form of a system of inequalities and equations. At that, it is necessary to clearly express the target of the problem, to explore the opportunities of applying the mathematical model to the given problem (Kravchenko, 1978). In the course of the mathematical analysis, the general properties of the model and its solution are identified. An important point here is the proof of existence of a solution of the formulated task. In the course of the study, the uniqueness of the solution, the trends and change limits of variables are defined. The choice of the mathematical method of the task solution is determined by the level of development of the computational mathematics and the belonging of the task being solved to a class (Kurnosov, 1977). The most common are the methods of linear programming (Kantorovich, 1960).

While determining the sequence of construction of the model, one must first formulate the optimality criteria, determine the production activities and their intensity, identify the structure of constraints, and develop technical and economic factors. The quantitative measure of the goal of the set task is characterized by the optimality criterion or the indicator of the goal achievement degree (Nemchinov, 1967). Selection of the optimality criterion must be justified theoretically and comply with the requirements of the mathematical method of the task solving. It is formulated as a function of input and output variables and parameters of the task, the value of which reaches a maximum or minimum for given conditions of this formulated task (Kundius, 2001). When selecting the optimality criterion, it is necessary to consider the consistency of the interests of all elements of the economic system under consideration. Preparation of background information is usually one of the most labor-consuming stages of modeling. At this stage, the methods of the probability theory, mathematical statistics, assessment of the data validity, and other methods are used (Bellman, 1974). The composition of species and methods of the production activity is determined by the problem's level of detail. 
At the stage of the numerical solution, the algorithms for solving the problem are developed, as well as software is prepared and the calculation is performed. As a rule, the calculations carried out with the help of economical-mathematical models are of multivariate nature. For many models, the numerical solution of the problem is the only one possible.

Very important in the initial stage is to analyze the sensitivity of the numerical results and their application. In this case, the most important issue about the correctness and completeness of the modeling results and their applicability in practice is solved. In the first place, the adequacy of the model should be checked by certain properties of the problem.

The stages of economic-mathematical modeling are closely interrelated, and there may occur their reverse connections. Depending on the set conditions, the economic efficiency is determined based on a specific criterion of optimality. The optimization plans of loading the machines at food plants may include the following information: volume of production, costs of production, prime cost, consumption of raw materials, material and other resources. When dealing with these criteria, one can use the method of linear programming, which is a rather efficient tool. In economics, constrained optimization problems arise in the practical implementation of the principle of optimality in the planning and management. The most important condition for the use of the optimal approach to the planning and management of production is the flexibility, the alternative nature of the production-economic situations in the circumstances of decision-making (Lependin, 2003). Optimality, or the best choice, is understood in this case as a certain economic indicator that allows comparing the effectiveness of certain managerial decisions. In practice, the criteria usually are the maximum profit, maximum profitability, maximum costs, and others.

\section{Results}

Modern meat and dairy enterprises are equipped with powerful and highly efficient production lines, the effective functioning of which is possible only if they are timely loaded with the raw materials of required volume and quality. The regularity of pace of provisioning the processing plants with raw materials is also very important. This raises the problem of determining the optimal production plans of agricultural enterprises with account of the needs of the processing enterprises in agricultural raw materials by periods of the year and the capacity of the agriculture (Dmitriev, 1987). Such an optimal production plan of agricultural enterprises will determine the size and structure of the crop and livestock sectors, the volume and structure of public procurement, the size of the necessary production resources, the scope of milk and cattle supply for processing in the determined periods of the year.

In turn, the optimal production plans of the meat and dairy enterprises will be determined with account of the capacity of the agriculture in providing the required amount, type, and quality of raw materials by periods of the year, their processing capacity, and the demand of the society for the final products. At the same time, it is also necessary to consider other sectors of the economy, which are engaged in storage, transportation, and sale of the products (Kardash \& Rapport, 1979). There emerges the need for coordination and balance of the inter-sectoral links of the agriculture, the meat and dairy industries, and other agricultural industries, as well as for development of such a planning solution that would take into account the above requirements, reflecting the approach to the agribusiness as a unified whole, and contribute to improvement of the efficiency of the meat and milk production (Speshilova, 2012).

The linking of the planning decisions of the agriculture and the industrial units of the agribusiness should be done not only by sectors, but also by territory, as it is necessary to coordinate sectoral plans of geographically disparate individual businesses that make up the local meat and dairy agribusiness. At that, such arrangement of the production plan of the agribusiness is feasible, which would provide for the most efficient production and the lowest total transport costs with the maximum output of the final products. Such a production plan of the local meat and dairy agribusiness can be called the optimal production plan or the best current territorial and sectoral structure. At that, the production planning in the local meat and dairy agribusiness assumes multiple variants of the planning decisions, which is expressed in the interchangeability of the methods of using the resources and the products and offers ample opportunities regarding variation of the amount and types of products manufactured by differently efficient technological methods of production (Braslavets \& Kravchenko, 1972).

Thus, the process of decision-making in the local meat and dairy agribusiness is a fertile soil for application of the optimal planning methods. Geographically, the considered local meat and dairy agribusiness encompasses several adjacent administrative areas. The agribusiness includes farms with different forms of ownership, meat and dairy enterprises.

An urgent and poorly approached problem is the poor scientific justification of regional forecasting plans of 
meat and milk production in the near future. Solution of the problem of optimization of the current planning of the local meat and dairy agribusiness allows determining the optimal annual production plan for the total of the interrelated agricultural, meat and dairy, and refrigeration businesses. The problem approach targets developing a scientifically justified plan of production of meat and milk, and other agricultural products by industries and enterprises of the agribusiness, as well as defining the rational specialization of agricultural and industrial businesses, the volumes of procurement and supplies of animal products for industrial processing, as well as the industrial output during a certain period. It is important to note that optimization of current planning of the local meat and dairy agribusiness is a complex problem. It can be successfully solved only if the industry specificity is taken into account in detail and the issues of the economics, organization, and technology of the production are taken into account as elements of a single process train. To adequately reflect the complex economic processes, the system of economic and mathematical models of the local meat and dairy agribusiness shown in Fig. 1 should be preferably used.

The system of models is designed for finding such an option of the annual production plan of the local meat and dairy agribusiness (with simultaneous optimization of transport links), which would provide for achievement of the given criterion of optimality at the most efficient use of available and centrally allocated resources and fulfillment of the planned tasks. The system takes into account all major inter-industry, intra-industry, and territorial links between the elements of the agribusiness in the "production - processing - storage implementation" chain with regard to the meat and dairy or other agricultural products.

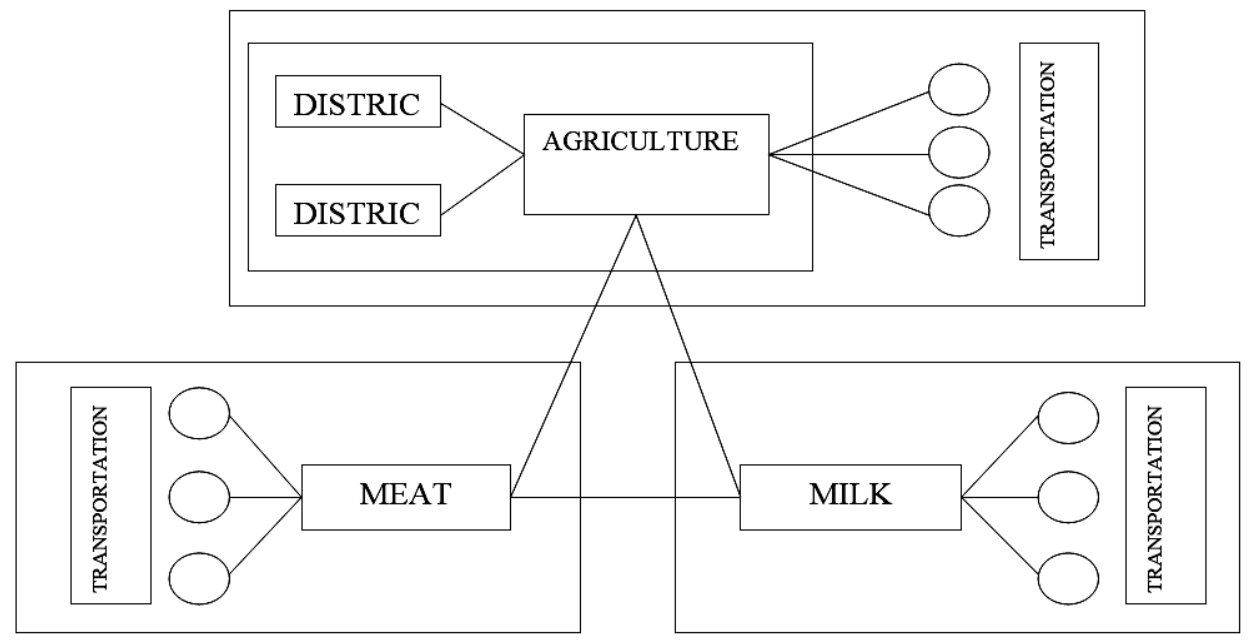

Figure 1. The system of models of the local meat and dairy agribusiness

The system consists of the following production models: "Agriculture", "Meat", and "Milk". Each of them reflects in detail the processes of production in the agriculture and the meat and dairy industries.

The "Agriculture" model considers agricultural businesses on an aggregated basis, within the administrative districts. The resulting planning decisions for the district as a whole are further "scattered" by farms of different ownership in the "District" tasks. If it is necessary to take into account the transport links, each of the production models can be iteratively linked to the transport models corresponding to it. In this case, it becomes possible for the system to best reflect the models of the most significant aspects of the process of agroindustrial integration provisioning with livestock raw materials of meat and dairy businesses by periods of the year with account of their needs and capacity of the agricultural production.

The "Meat" and "Milk" sectoral models, as well as the "Agriculture" and "District" models are applied in practice with various modifications of the known models of agricultural production. Their modernization resides in separation of the branches of beef and dairy cattle production. To optimize the transport links with regard to transportation of raw materials, semi-finished and finished products, the transport tasks are usually used. At that, it is envisaged that the capacity of suppliers and customers are determined after solution of the relevant production tasks. This approach allows considering the process of production of meat and milk from the standpoint of the unified whole. The optimal plan of final production of local meat and dairy agribusinesses is calculated.

The general logic scheme of calculations according to this system of models is as follows: first, models of the 
higher level provide information about the tasks of production of finished products of the agribusiness and the limits of resources allocated to all sectoral subsystems of the agribusiness. Then, using this information, the production models "Agriculture", "Meat", and "Milk" are solved and linked with each other within the framework of the "big" iterative process.

The resulting optimal production plan of the agricultural subsystem of the agribusiness is advised to specific executors - various farms - by coupling the "Agriculture" - "District" tasks within the "small" iterative process.

When one needs optimization of the transport links at each step of larger iterations, the medium iterative processes appear with regard to coupling the transport and production tasks being solved.

Thus, the particular implementation of the system of models allows determining the best current plan of production of final products of the agribusiness with regard to all businesses included in it. In other words, optimization of the current structure of local production of the meat and milk agribusiness takes place in the sectoral and territorial contexts (Kuev, 2009).

From the perspective of the development of specialization on the basis of inter-farm cooperation, the most important issue is the cost-benefit analysis required for the comparative correlation and evaluation of the results in each period. Efficiency of specialization is defined through the generalizing and specific indicators, such as profitability, profit, prime cost, capital productivity, and labor productivity. Specialization of production is one of the ways to improve the effectiveness of the intensification of livestock production. Rational specialization, creation of breeding facilities allows increasing the production, improving its efficiency and solving the socio-economic problems of organization and technology of the production.

\section{Discussion}

Broad specialization - creation of individual farms specializing mainly in the production of milk, breeding young stock to supplement the dairy cattle in other farms, or fattening cattle.

In the circumstances of interfarm cooperation, the industrial relations of people improve, and their interest in the development of production of all business units united by the common production process increases. However, specialization is accompanied by the trend of production integration, creation of interfarm agroindustrial associations, in which agricultural production is organically linked to the industrial processing of its products.

The performance indicators of specialization are the maximum production and minimum costs, and of self-supporting efficiency - the profitability, which deals with economically justified pricing that can be achieved by improving the economic soil fertility and increasing the yield per hectare of land.

Implementation of specialization, concentration of production on the basis of interfarm cooperation is often accompanied by decrease in production costs, increase in economic efficiency and productivity. Specialization of dairy farming as the main form of social division of labor is of versatile nature. For example, specialization of employees at dairy farms and facilities in individual production sites (milking, feeding, etc.) allows more qualified performance of certain technological operations of the cattle servicing. This makes it possible to increase the labor productivity, and to reduce the overall cost of labor for the production of one hundredweight of milk. Specialization of labor of masters of machine milking, feeding operations, manure removal, etc. is rather important.

The in-farm specialization's distinctive feature is that by concentration at a single farm of homogeneous by physiological and economically valuable traits of cattle in the milking herd or bred rearing stock, specialized teams of highly skilled service of the relevant groups of animals are created.

Analysis and evaluation of the efficiency of the association of dairy plants are an important step in the financial analysis of the activity of each of these businesses. At this stage, one of the purposes of the economic analysis is to find in-farm reserves, taking into account the various options of strategic decisions to manage the enterprise.

The immediate objective of production is to generate profit. This economic indicator creates a certain guarantee for future operation and development of the company, helping to tackle the impact of uncertainties and risks associated with the activities of a processing enterprise.

In the market conditions, an enterprise should strive to gain at least the amount of profit that not only would allow it to maintain its position on the market, but also ensure further development.

Estimation of economic efficiency, as a rule, requires consideration of the costs and benefits associated with the implementation of a specific planned strategy. In this case, the estimate of future costs and benefits in determining the cost-effectiveness should be carried out within the calculation period. At that, the comparison of multi-temporal parameters is carried out by bringing (discounting) them to the value in the initial period. 
Discounting of capital costs and profits is performed with account of the fact that financial resources have a temporal value.

In the model of optimization of the structure of production of an agro-industrial association, the assessment of the discounted profit over the estimated period less capital expenditures required for the implementation of the plan is used as the optimization criterion (Kolesnev, 2009).

Analysis and evaluation of the economic efficiency of performance of the enterprises that are members of an agro-industrial association are a very important stage of the financial analysis of the cooperative formation as a whole. Efficiency can be seen from different angles: from the standpoint of costs, output planning, profits, internal reserves at the analysis of variant strategic decisions on enterprise management aimed at specific goals. The main goal in the market conditions is to maximize the profit. However, taking into account the fact that in most cases economic tasks assume achieving several economic performance indicators at a time, these tasks can be solved by the methods of vector optimization.

It is offered from the position of the interest of enterprises that are members of agro-industrial associations to use as a criterion the sum of the discounted profit over the estimated period, received by optimization of the association development plan less capital expenditures required to implement the plan (taking into account the interest rate on loans needed to perform the program), or the share of this criterion. Balanced development of the agribusiness through the optimization of intersectoral proportions is one of the most important functions of the economy management (Hachemizova, 2009). Concentration of capital investments in the priority areas of development requires optimization of intersectoral proportions on the basis of economic and mathematical modeling.

From the perspective of system approach, the region's agribusiness is represented as a complex hierarchical system comprising interconnected food subsectors (the cereal, milk, meat, and other subsectors). In its turn, each food subsector is a subsystem of interrelated sectors producing one or several types of final products (Khomyakov, 2003). One of the possible options in the methodical plan of optimization of the production-sectoral structure of the agribusiness is the consistent aggregation of subsectors up to optimization of its structure as a whole. With this approach, there is no need to develop a complex unified model of the agribusiness with a detailed description of conditions of individual sectors' operation.

Modern dairy enterprises are equipped with powerful and highly efficient production lines, the effective functioning of which is possible only with the timely supply of raw materials of required volume and quality. Another important aspect is the rhythm of supplying raw materials to these enterprises, which raises the task of optimization of agricultural enterprises' production to meet the demand of the processing enterprises for agricultural raw materials for various periods. This task allows determining the size and structure of the crop and livestock sectors, the amount of necessary resources, the objects of milk supply for processing (Lenkov, 1979). As the tasks are solved, there appears the need for coordination and balance of inter-sectoral linkages of the agriculture, the meat and dairy industries, and other sectors of the agribusiness. The decision-making process in the local dairy agribusiness offers many opportunities for application of the optimization methods.

Based on the financial and economic analysis of the two plants, one can conclude that improvement of the efficiency of production is possible in case of development of rational methods of cost management. For example, at one of the plants, the high costs of milk production are not offset by the proceeds from its sale. Of course, it is necessary to take measures to reduce the levels of components containing costs.

The "Agriculture" production model is designed to determine the optimal current production plan of the aggregated agricultural enterprises. It adequately reflects the process of agricultural production, with a special focus on the livestock production. At the same time, it provides for seasonally adjusted annual meat and milk production, inter-sectoral linkages (direct and reverse) of the agriculture, the meat and dairy industries. Also, it reflects the possibility of maneuvering resources, the interchangeability of the ways of using the resources and products, both between districts and between sectors. The model formalizes the balances of the basic production resources of the agricultural production (land, labor, feed, fertilizers) and the supply of milk and livestock to the processing elements, and the general economic balances (Aghanbegyan (Ed.), 1988).

The calculations determine the optimal structure and size of sectors of the agricultural production, the volume of public procurement of products by the districts of the agribusiness, the volume of milk and livestock by the types for processing from the districts by periods of the year. The maximum profit is taken as the model optimality criterion.

The "Milk" production model is designed to determine the optimal current production plan of the dairy 
enterprises of the agribusiness and the corresponding refrigerators, which plan is correlated with the plan of production of the whole local meat and dairy agribusiness. The model in detail reflects the processes of production of dairy products by the stages: "delivery of raw materials - processing in the I element - storage processing in the II element - sale"; the seasonality of production and inter-sectoral connections of the dairy industry, agriculture, and the meat industry are taken into account. The model provides for the interchangeability of the ways to use the resources and products. Limitations of the model reflect the balances on the use of raw materials, semi-finished and finished products, the use of basic production resources (capacity of enterprises, storage tanks, etc.), as well as restrictions on the plans of industrial production. Optimization of the structure and the industrial output by enterprises and by periods of the year is carried out.

The "Meat" production model is designed to optimize the production plan of the meat enterprises of the agribusiness and the corresponding refrigerators, which plan is correlated with the plan of production of the whole local meat and dairy agribusiness. The model in detail reflects the processes of production of meat products by the stages: "delivery - fattening - slaughter - storage - meat processing - sale"; the seasonality of production and inter-sectoral connections of the meat industry, agriculture, and the milk industry are taken into account; reflects the interchangeability of the ways to use the resources and products; provides for the balances on the use of raw materials, semi-finished and finished products, basic production resources (capacity of enterprises, storage tanks, etc.), as well as restrictions on the plans of industrial production; singles out the optimal structure and industrial output by enterprises and by periods of the year. The maximum profit is taken as the model optimality criterion.

The linkage of the "Agriculture" - "Meat" - "Milk" models is carried out within the framework of the big iterative process.

The "District" production models are designed to determine the optimal current production plan of various farms of the agribusiness, correlated with the plan of production of the whole local meat and dairy agribusiness. As the "District" models are based on the pattern of the "Agriculture" model, they have the same variables and constraints as this model does. The difference is that all components in the "District" model characterize the production activity of individual farms.

Thus, the "District" models also fairly completely reflect the agricultural production processes in the with separation of the milk and meat production.

The solution of the "District" model determines the optimal structure and sizes of the sectors, the volume of purchases of products in specific farms of the sector, volume of milk and livestock supplies by types for processing from the farms by periods of the year. The maximum profit is taken as the optimality criterion.

The coupling of the "Agriculture" - "District" models is carried out within the framework of the small iterative process built in accordance with the ideas of the method of coordination of plans of V.D. Marshak (Rozin et al., 1988).

If optimization of the transport links between the enterprises of the agriculture, the meat and dairy industries, and the refrigerating entities of the local meat and dairy agribusiness is required, the transport models are used with regard to transportation of raw material, semi-finished and finished products, and industrial wastes. At that, the suppliers' capacity and consumers' demand for a certain product are determined by solution of the relevant production task. Coordination of their results and selection of an agreed version of the plan are carried out within the framework of the average in our system iterative process using the principle of compositional planning.

\section{Conclusion}

The local meat and dairy agribusiness cannot exist in isolation from other subsystems of the economy, particularly, it operates at the regional level together with similar local systems. The interconnection of the studied agribusiness with the regional (and neighboring local) agribusinesses is implemented through the information on tasks and resources. As noted above, the model of regional agribusiness provides information on the volume of output of the final products of the agribusiness and limits of the allocated resources, which forms the main constraints of the "Agriculture" model; in turn, from the bottom up comes the information on the potential production of each local agribusiness, their need in resources, as well as local estimates. At a higher level, based on this information, adjustment of decisions is made. Optimization of the production and sectoral structure will ensure a stable balance in the process of expanded reproduction with the effective operation of the system from the perspective of a given criterion. The optimality criterion is: the maximum production of the final product with limited resources; the maximum efficiency in the use of resources while ensuring the desired output of the final product, etc. 


\section{References}

Aganbegyan, A. G. (Ed.). (1988). Economic-mathematical methods in planning multi-sector complexes and industries (p. 417). Novosibirsk: Nauka.

Bellman, R., \& Angel, E. (1974). Dynamic programming and partial differential equations (p. 205). Moscow: The "Mir" Publishing House.

Bernstein, F. (2004). A general equilibrium model for industries with price and service competition. Federgruen Awi Over. Res., 52(6), 868-886.

Braslavets, M. E., \& Kravchenko, R. G. (1972). Modeling of economic processes in agriculture (p. 589). Moscow: Kolos.

Cuev, A. I. (2009). Mathematical Simulation Economic Processes in the Agriculture Economy (p. 405). Maikop: Maikop Univ Bauman.

Dmitrieva, G. M. (1987). The use of the economic-mathematical model of in-farm allocation at determining the job-plan for the farm's divisions. The use of economic-mathematical methods and computer technology in agriculture /collection of scientific papers. Novosibirsk: Novosibirsk Agricultural Institute.

Hachemizova, E. A. (2009). Factors of socio-economic development and regional competitiveness. Herald of the Bauman Moscow Technical State University, 3.

Kantorovich, L. V. (1960). Best Use of Economic Resources (p. 348). Moscow: Academy of Sciences of the USSR.

Kardash, V. A., \& Rapport, E. O. (1979). Modeling of economic processes in agriculture (p. 215). Novosibirsk: Nauka.

Khomyakov, S. V. (2003). Simulation of reproductive processes in equilibrium diversified economic system. thesis of Candidate of Economic Sciences, Южно-российский государственный технический университет (НПИ), Novocherkassk.

Kolesnev, V. I. (2009). Economic-mathematical methods and models in the field of agriculture: A Handbook. Part 4 (p. 102). Minsk: SE "Training Center of the Ministry of Agriculture".

Kravchenko, R. G. (1978). Mathematical Modeling of Economic Processes in agriculture (p. 200). Moscow: Kolos.

Kundius, V. A. (2001). Mathematical Methods in Economics and modeling socio-economic processes in Agribusiness Training Manual (2nd ed., revised and ext., p. 201). Moscow: Kolos.

Kurnosov, A. P., \& Sinelnikova, M. M. (1977. Computing and economic-mathematical methods in agriculture: Textbook (p. 328). Moscow: Statistika.

Lenkov, I. I. (1997). Economic-mathematical modeling of economic systems and processes in agriculture (p. 304). Minsk: DizaynPRO.

Lependin, M. O. (2003). Optimization of parameters of production in agricultural enterprises and private farms in the transformation. Thesis of Candidate of Economic Sciences, Воронежский государственный аграрный университет имени К.Д. Глинки, Voronezh (p. 172).

Nemtchinov, V. S. (1967). Selected Works in six volumes. Tom. 3 Economics and Mathematical Methods (p. 490). Moscow: Nauka.

Pasternak, P. P. (2009). Estimates on the resources in the economy (p. 152). St. Petersburg: Prospekt Nauki.

Rozin, B. B., Suvorov, B. P., \& Marshak, V. D., et al. (1988). Economic-Mathematical Methods in planning multisectoral complexes and industries (p. 413). Novosibirsk: Nauka, Siberian Branch.

Speshilova, N. V., Shevrin, E. V., \& Korabeynikova, O. A. (2012). Economic-mathematical models and their practical application in agriculture: Textbook (4th ed., rev. and ext., p. 132) Orenburg: Publishing Center Gray.

\section{Copyrights}

Copyright for this article is retained by the author(s), with first publication rights granted to the journal.

This is an open-access article distributed under the terms and conditions of the Creative Commons Attribution license (http://creativecommons.org/licenses/by/3.0/). 